\title{
Acute spinal epidural abscess. Observations from fourteen cases
}

\author{
G. E. Phillips \\ F.R.C.S.
}

\author{
A. JEFFERSON \\ F.R.C.S.
}

Department of Neurological Surgery, The Royal Infirmary, Sheffield S6 3DA

\section{Summary}

Fourteen cases of acute spinal epidural abscess are analysed. Postoperatively 6 recovered completely, 4 patients recovered enough to allow unaided walking, 2 died and 2 who were paraplegic pre-operatively remained so.

The purpose of this paper is to remind readers of the existence of this condition and to plead for early diagnosis and prompt surgical treatment.

\section{Introduction}

Spinal epidural abscess is a condition which has been well documented, mainly in American literature but notably in this country by Stammers (1938) and Hulme and Dott (1954). Despite all that is known about this condition, the diagnosis is still being made too late with the disastrous consequence to the patient of permanent paraplegia.

The condition based on an analysis of 14 patients treated for acute spinal epidural suppuration referred to the Department of Neurosurgery at Sheffield Royal Infirmary over a 17-year period, 1957-1973, is now reviewed.

\section{Typical symptoms and signs}

The patient, who will be febrile $\left(99-104^{\circ} \mathrm{F}\right)$ and may have suffered from a recent infection, such as a boil, complains of an ache or pain in the back occurring at the level of epidural infection. The pain becomes very severe later and it is the intensity of this pain which is outstanding and diagnostic. Stammers (1938) noted that this pain is increased by flexion of the spine as opposed to extension. If the diagnosis is not made and the pus is not released, sooner or later abnormal neurological signs develop. Initially these will comprise paraparesis with weakness or sensory loss of the lower limbs or retention of urine. However, without treatment this paraparesis will inevitably become a paraplegia.

Rankin and Flothow (1946) noted 4 stages in the disease, namely spinal ache; root pain; impaired cord function (sphincter loss, motor loss, sensory loss); complete paralysis.

In order to have a proper concept of the urgency with which diagnosis must be made and the pus evacuated, it is essential to be aware of the fact that the time interval between the stage of no or minimal neurological abnormalities and complete irreversible paraplegia can be as little as $2 \mathrm{hr}$.

\section{Ancillary investigations}

Contrast myelography may aid in assessing the level of the lesion but in inexperienced hands this could be misleading for there is not necessarily a complete block beneath the lesion and an incomplete block may be missed on myelography. Intrathecal isotope myelography may indicate an incomplete block (Yeo and Collins, 1974) but the needle at lumbar puncture may not enter the subdural space or may leak and give false readings? However, this method has been used for detection of the spinal epidural abscess (Perryman, Noble and? Braydon, 1958).

Myeloscintigraphy following the intravenous injection of radioactive substances would be a useful aid if it could be done quickly enough in a neurosurgical centre. In one patient seen in the Royal Infirmary the granulation tissue adjacent to an acute lower thoracic disc prolapse had concentrated the isotope sufficiently to be easily recognizable, so presumably the granulation tissue adjacent to an epidural abscess would behave similarly. The authors could find no record of this method of investigation being used in spinal epidural abscess, although von Piepgras and Velts (1970) suggested that it could be used in detection of abnormal pathological processes in the spinal canal. Technetiun diphosphonate has been observed to accumulate in a pyogenic abscess not involving bone (Merrick, 1974). In addition, pyogenic infection of bone has been investigated with intravenous scintigraphy. Because acute epidural spinal abscess is often associated with vertebral infection, the potential value of scintigraphy is sufficient to merit giving it a trial as a diagnostic weapon in spite of the fact that Kemp et al. (1973) reported that there was no increased uptake of the intravenous radioactive fluorine and strontium in relation to soft tissue lesions such as paravertebral abscess. 
Two cases which illustrate the penalties of delays in diagnosis are described.

\section{Clinical material}

In the 14 cases, the ages ranged between 9 and 60 years, there being 5 female and 9 male patients. In each case the epidural abscess was acute, being present in the thoracic, or lumber region, or in one case in both.

\section{Case 1}

This 20-year-old woman was admitted to the Neurosurgical Unit in August 1957. She was perfectly well until 7 days before admission, when she awoke with pain in the upper lumbar region. Over the next 3 days the pain became more severe and she became febrile. She was then admitted to her parent hospital. On the following day she began to get a feeling of cramp in her legs. A lumbar puncture was performed which revealed CSF with a 'lot of red cells', no white cells and a protein level of $90 \mathrm{mg}$. A Queckenstedt's test was negative. At this stage a diagnosis of epidural abscess was contemplated. The next day the patient's legs became progressively 'curious' so that by late that night she had lost all sensation and use of her lower limbs. One day later she was transferred to a Neurology Unit where a sensory level at D10 was found. Another lumbar puncture revealed no fluid and only a little fleck of yellow material. A diagnosis of epidural abscess was made. On admission to the Neurosurgical Unit there was a total sensory loss to D9 with a slightly shelving level at D8 and a flaccid paraplegia with bladder paralysis. Exploratory laminectomy was performed at once without resort to myelography. A localized spinal epidural

TABle 1. Details of 14 patients with spinal epidural abscesses. Staphylococcus pyogenes was isolated from each except no. 3, from which Proteus sp. was isolated

\begin{tabular}{ccccc}
\hline $\begin{array}{c}\text { Patient } \\
\text { No. }\end{array}$ & $\begin{array}{c}\text { Sex and } \\
\text { age } \\
\text { (in years) }\end{array}$ & $\begin{array}{c}\text { Level of } \\
\text { lesion }\end{array}$ & $\begin{array}{c}\text { Probable } \\
\text { mechanism } \\
\text { of infection }\end{array}$ & $\begin{array}{c}\text { Time-lag } \\
\text { from onset } \\
\text { to surgery } \\
\text { (days) }\end{array}$ \\
\hline 1 & F (39) & T1-T10 & Coryza & 7 \\
2 & M (37) & $\begin{array}{c}\text { L4-L5 } \\
\text { L4-L5 }\end{array}$ & Neck abscess & 10 \\
3 & F (53) & & - & 30 \\
4 & F (20) & D9 & - & 7 \\
5 & M (48) & T5-L2 & Back injury & 21 \\
6 & M (54) & L5 & - & 4 \\
7 & M (17) & T1-L5 & Back injury & 7 \\
8 & M (36) & L3-S1 & - & 15 \\
9 & M (26) & L1-S1 & Febrile illness & 7 \\
10 & M (52) & T7-T12 & Diabetes mellitus & Same day \\
11 & F (49) & L4-L5 & Post-op. & 8 \\
12 & M (9) & L4-L5 & - & 30 \\
13 & M (16) & L3-L4 & Back injury & 12 \\
14 & F (60) & T7-T8 & Diabetes mellitus & $21-28$ \\
\hline
\end{tabular}

abscess was found situated under the laminae of D8, 9 and 10. This was more extensive on the left side of the spinal cord than the right. The muscle was closed in 2 layers with catgut and with silk to skin. Two tubes were placed in the region of the abscess and penicillin irrigation commenced. Penicillin was also administered intramuscularly. Culture of the pus revealed pure growth of Staphylococcus pyogenes sensitive to penicillin.

Owing to the considerable delay in diagnosis the patient suffered irreversible damage so that she was left with a spastic paraplegia with no return of sensation below the level found before operation.

\section{Case 2}

This 16-year-old youth was admitted to the Neurosurgery Unit in July 1969. Twelve days previously he had fallen and injured his back at work. He went home but 2 days later found he was having trouble initiating micturition. Again 2 days later his legs felt weak and heavy. He consulted his family doctor and apparently a disc lesion was diagnosed. He was unable to walk home and had to be driven there. At about this time he also complained of difficulty in initiating defaecation. Three days later he was admitted to another hospital with a 6-hr history of retention of urine, pain over the lumbar region and weakness of both legs. $\mathrm{He}$ also had limited movements of his spine due to pain. A lumbar puncture was performed which revealed pus - this grew a coagulase-positive Staphylococcus sp. A diagnosis of epidural abscess was made and he was then admitted to the Royal Infirmary. On admission he was pyrexial and the power in his lower limbs was markedly diminished, the right more than the left. He had areflexia in his lower limbs and the plantar responses were equivocal. Sensation appeared to be diminished to light touch and vibration sense up to D10. He was unable to flex his spine more than $40^{\circ}$ and he was tender over L3-4 region. Laminectomy was performed from L1-L5 inclusive, revealing an extradural abscess and black necrotic fat. Two drains were laid in the epidural space and cloxacillin and streptomycin instilled through these. Following the operation he was able to micturate normally and gradually power increased in his legs. At follow-up 3 years later he had made a complete recovery in sensation but had some residual weakness of the quadriceps of his right leg and weakness of his left gastrocnemius. This did not prevent him from walking.

\section{Results}

Six patients recovered completely after operation. Three of these had no abnormal neurological signs pre-operatively. The fourth had retention of urine and some sensory loss at L1 and L2 and sacral areas. 
The fifth had weakness and diminished reflexes in the right lower limb and the sixth had complete loss of use of the right tibialis anterior muscle, depression of knee jerks and a sensory level at L5 with sacral sparing.

Two patients had more obvious abnormal neurological signs pre-operatively. One developed an acute spinal epidural abscess following laminectomy elsewhere for acute disc prolapse. She manifested weakness of both lower limbs together with a loss of sensation below D7. Eventually, following operation for release of the abscess, the patient was able to walk with the aid of a full-length caliper on one leg, but had bladder symptoms and a sensory level to D7. The second case was Case 2 described above.

Of 4 patients who were paraplegic pre-operatively, 2 remained paraplegic after operation (one of these was described above as Case 1). The third had lower limb spasticity but was able to walk, and the fourth had moderate spasticity of both legs but was able to stand with calipers.

Two patients died. Both suffered from diabetes mellitus and were on treatment with insulin. The first presented with paraparesis with retention of urine. She was treated surgically with some improvement in her physical signs but died one month later from the effects of renal abscess and pyelonephritis. The other also presented with paraparesis and retention of urine, but her general condition was too poor to allow operation. At post-mortem an epidural abscess was found at D7-D8 region.

\section{Discussion}

Acute spinal epidural abscess is usually caused by a coagulase-positive $S$. aureus, although other organisms such as Proteus and Pneumococcus have also been isolated. The organism reaches the epidural space via the blood stream or by local implantation. Trauma to the spine may produce a haematoma, thus creating a niche for growth of blood-borne organisms. The organisms may produce infection directly by growing in traumatized fat or in haematoma, or may produce septic thrombophlebitis in the epidural space following septic emboli. When the inflammatory reaction is acute, the culminating infection reaches the stage of pus formation within days. The abscess produces its effects either by acting as a space-occupying lesion or else by thrombosis or stasis of blood in vessels entering and leaving the spinal cord; stasis may also be caused by staphylococcal exotoxins. The pathological changes occurring in the spinal cord include vacuolization and liquefaction with all stages of degeneration of neurones up to death (Browder and Meyers, 1941). Any level and a considerable length of the vertebral canal may be involved. Hulme and Dott (1954) recorded one patient in whom the abscess involved the whole length of the vertebral canal. Most cases, however, occur in the upper and midthoracic regions. This is thought to be due to the fact that the epidural space is of greater width between the 4th and 8th thoracic vertebrae. It is also wider below the second lumbar vertebra, and abscesses frequently occur below this site. Treatment must be instituted early and should consist of laminectomy to release the accumulated pus. Specimens of the pus must be sent for culture and sensitivities. Two or more catheters are left in the bed of the abscess and brought out through stab incisions adjacent to the main wound. The relevant antibiotics are then given systemically and also instilled through the tubes. In one of the authors' patients, extensive laminectomy from L1-S1 was required for the abscess where some osteomyelitis was also present. This patient developed a spondylolisthesis at L4-L5 L5-S1 postoperatively which did not progress, but the possibility of this occurring must be kept in mind. A spinal corset was necessary for support. Heusner (1948) also removed 7 laminae in this condition and no spinal support was required later. Hulme and Dott (1954) noted that in children the laminae should be elevated as a continuous string so that they may be replaced, thus preventing kyphosis later.

The histories of the patients in this series show that the results chiefly depend on the rate of progress as the abnormal neurological signs rather than on the time interval between the onset of symptoms and the onset of abnormal neurological signs; it must again be stressed that paraplegia can occur in as little as $2 \mathrm{hr}$ from the onset of neurological symptoms. A paraplegia of such rapid onset carries a bad prognosis and may be irreversible, but immediate surgery is necessary to save life, and occasionally good results can be attained. Six of the 14 patients discussed were treated originally in other hospitals with antibiotics alone. Despite this, the condition progressed and laminectomy had to be performed later to release the pus. In accordance with general surgical principles successful treatment of this condition necessitates drainage of the abscess, with antibiotics employed only as adjuvant treatment.

The stress in this paper has been laid on early diagnosis and treatment by surgery. Failure to conform to these principles is still resulting in permanent paraplegia in many unfortunate victims of this disease. Heusner has justly said, 'there is no more justification for the diagnosis of this disorder to await the appearance of paralysis than for the diagnosis of a brain tumour to await coma'. In the present authors' opinion this remark should be linked with the saying, "very intense back pain in the febrile patient constitutes sufficient grounds for urgent referral to the nearest neurosurgical unit'. 
To follow such a policy may lead to some unnecessary referrals but it would ensure that those who might be developing a spinal epidural abscess could receive treatment early enough to avoid permanent neurological deficits.

\section{References}

Browder, J. \& Meyers, R. (1941) Pyogenic infections of the spinal epidural space. Surgery, St Louis, 10, 296.

Heusner, A. Price (1948) Non-tuberculous spinal epidural infections. New England Journal of Medicine, 239, 845.

Hulme, A. \& DotT, N.M. (1954) Spinal epidural abscess. British Medical Journal, 1, 64.

KeMP, H.B.S., JohNS, D.I., MCAlister, J. \& Goodlees, J.N. (1973) The role of flurine 18 and strontium 87 in scintigraphy in the management of infective spondylitis. Journal of Bone and Joint Surgery, 55b, 301.
MerricK, M.V. (1974) Review article - bone scanning. British Journal of Radiology, 48, 327.

Perryman, C., Noble, P. \& Bragdon, F. (1958) Myeloscintigraphy: a useful procedure for localization of spinal block lesions. American Journal of Roentgenology, 80, 104.

Rankin, P. \& Flothow, P. (1946) Pyogenic infection of the spinal epidural space. Western Journal of Surgery, Obstetrics and Gynecology, 54, 320.

STAMmERS, F.A.R. (1938) Spinal epidural suppuration with special reference to osteomyelitis of the vertebrae. British Journal of Surgery, 26, 366.

von Piepgras, U. \& Velts, P. (1970) Die szintingraphische Erfassung pathologischer Prozesse des Spinal Kanals nach Intravenoser. Applikation von radioaktiven Testsubstanzen (i.v. Myeloszintigraphie). Fortschritte auf dem Gebiete der Rontgenstrahlen und der Nuklearmedizin, 113, 329.

Yeo, T. \& Collins, LeE (1974) The place of isotope myelography in the definition of spinal cord swelling following trauma: an experimental study. Australian and New Zealand Journal of Surgery, 44, 292. 